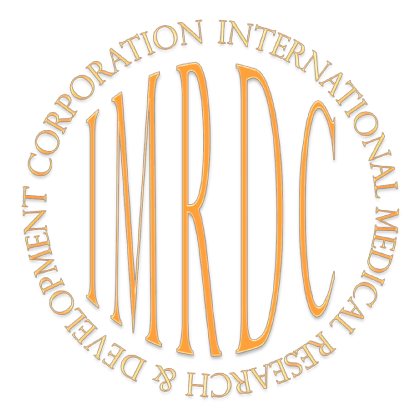

\title{
A Pressure Sensor for an Electrode System in Transpalpebral Rheoophtalmography
}

\author{
Dmitry M. Shamaev ${ }^{1 *}$; Petr V. Luzhnov, $\mathrm{PhD}^{1}$; Elena N. Iomdina, $\mathrm{PhD}, \mathrm{ScD}^{2}$ \\ ${ }^{1}$ Bauman Moscow State Technical University \\ ${ }^{2}$ Moscow Helmholtz Research Institute of Eye Diseases \\ Moscow, the Russian Federation
}

\begin{abstract}
A method of pressure registration in transpalpebral rheoophtalmography (TP-ROG) is proposed. Possible construction solutions of this method are presented, including sensor types and their technical parameters. One such solution (a resistive pressure sensor) was incorporated in a TP-ROG electrode system. The system was used to measure the sensitivity and linearity of this pressure sensor. (International Journal of Biomedicine. 2018;8(2):159-161.)
\end{abstract}

Key Words: transpalpebral rheoophtalmography $\bullet$ bioimpedance $\bullet$ electrode system $\bullet$ pressure sensor $\bullet$ eye

\section{Introduction}

Impedance diagnostic methods have been used in ophthalmologic practice. ${ }^{(1,2)}$ Rheoophtalmography allows investigating ocular hemodynamics in physiological conditions. ${ }^{(3,4)}$ In particular, it can be used to assess the hemodynamic state in the anterior segment of the eye. ${ }^{(5)}$ In recent years, TP-ROG has been used for certain eye diseases, including myopia, diabetic retinopathy, and glaucoma. ${ }^{(5,6)}$

In the reported work, TP-ROG signals were registered by a technique that makes use of tetrapolar TP-ROG ${ }^{(5)}$ : Four electrodes were positioned on an upper eyelid surface and arranged in a straight line. The two measuring electrodes were placed between the two current electrodes. The contact area diameter of an electrode was $4 \mathrm{~mm}$. The electrodes were made of copper, with subsequent silvering, so that the silver layer was no less than 20 microns thick. ${ }^{(7)}$

To achieve high quality TP-ROG signal recording, it is important that the force applied to the rheographic electrodes on the eyelid be controlled. During TP-ROG recording, base impedance (BI) of biological tissues is recorded. The $\mathrm{BI}$ is affected by the characteristics of the biological tissues and by the pressure that the electrode system applies to the eyelid.

The degree with which the electrode system presses on

*Corresponding author: Dmitry Shamaev. Bauman Moscow State Technical University, Moscow, the Russian Federation. E-mail: shamaev.dmitry@yandex.ru the eyelid should be regulated to ensure the required quality of the TP-ROG signal and to minimize the effect the electrode system might have on the normal condition of the eye. ${ }^{(8)}$ It is for this reason that TP-ROG electrodes should always be monitored for the pressure they exert on the eyelid.

\section{Materials and Methods}

In the course of the research, it was found that with insufficient force applied to the electrodes, it is impossible to register a TP-ROG signal. ${ }^{(5)} \mathrm{A}$ minimum pressure is necessary to secure the contact between the electrodes and the skin. On the other hand, too strong a pressure reduces the reliability of the received signals and increases the number of signal distortions. In addition, excessive pressure on the eye increases the discomfort of the subject examined. Consequently, the method must have means to control the force affecting the electrodes. The control system can be either separated from or embedded into the design of the electrodes. Figure 1 illustrates how the whole system involving the measurements and force control operates. Possible options of system implementation are outlined below.

The pressing force can be registered with the help of piezoelectric sensors or resistive sensors. We have considered the piezoelectric sensor options with built-in and external electrodes. The manufacture of original piezoelectric sensors is difficult because serially produced samples with a diameter less than $5 \mathrm{~mm}$ and the required polarization vector are not 
available on the market. We finally opted for a sensor produced by Honeywell. It is a piston sensor in a small enclosure with dimensions of $12.7 \times 10.3 \times 8.0 \mathrm{~mm}$. The declared error of the sensor is $0.5 \%$. The development of the design using this sensor implies the necessity of placing the sensor on a separate electrode that transmits the clamping action.

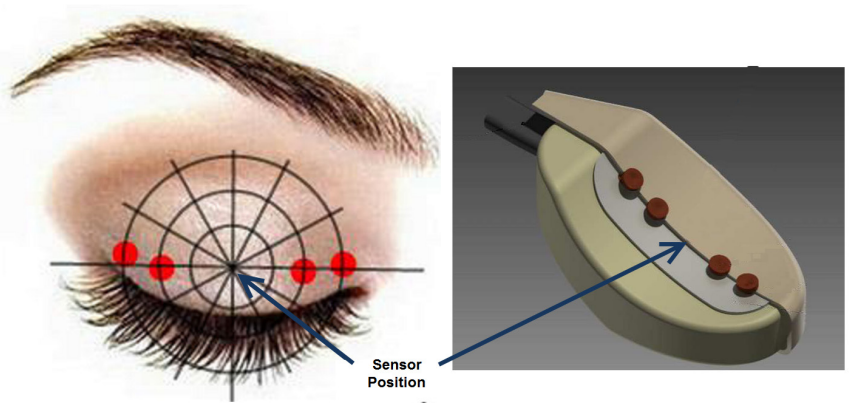

Fig. 1. Pressure sensors position in diagnostics using TP-ROG

Thus, the force exerted by the fastener system will be transmitted to the eye by means of this sensor. In this case, the control of the pressing force of the electrodes will be carried out with a low accuracy. A similar problem occurs when placing the sensor on any of the electrodes being used because the uniformity of pressure exerted by the electrodes on the eyelid is lost. Increasing the thickness of the substrate complicates the procedure of applying electrodes as it is difficult to control their location.

One construction possibility we considered was to place the sensor next to the electrode system rather than directly within it. Since the piston has a smaller diameter as compared to the enclosure in which it is located, it is extremely difficult to fix the sensor perpendicular to the surface. Therefore, a special lining was made, supplied with pins to fabricate holes on the sensor. Regardless of the angle of inclination of the sensor axis, the force is transmitted to the sensor piston and not to its enclosure. The sensor is installed on a special base, which is fixed to the position control system. The construction is designed in such way that it can be easily moved along the lead system.

The tests showed that the construction is easy to use and allows registering the pressing force at any point along the line of the electrodes. However, piezoelectric sensors have a high sensitivity to the overlapping errors. Therefore, the solutions based on resistive diaphragms were found to be more preferable, and were eventually used in the construction of the developed system. Sensors from Interlink Electronics or Parallax Inc are suitable.

The construction options of applied force sensors in TPROG electrode system are as follows:

a) Disks of varied diameters. For their use, it is necessary to manufacture additional elements (Fig. 2a).

b) Resistive tapes. Such sensors can be installed along the line of all electrodes (Fig. 2b).

Types of the sensors proposed are presented in Figure 3. The main technical characteristics of sensors are specified in Table1.

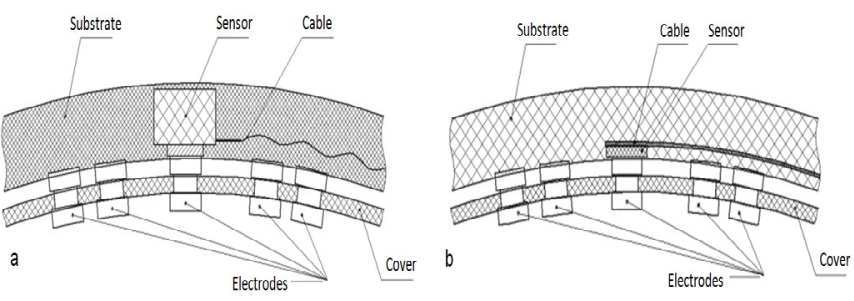

Fig. 2. Constructions with applied force sensors for TP-ROG electrode system.

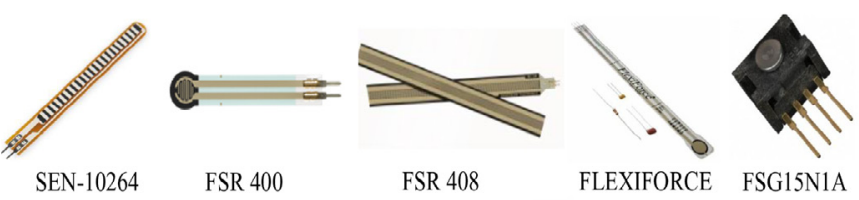

Fig. 3. Sensor types.

Table 1.

The Main Technical Characteristics of Sensors

\begin{tabular}{|l|c|c|c|c|c|}
\hline $\begin{array}{l}\text { Main technical } \\
\text { characteristics }\end{array}$ & $\begin{array}{c}\text { SEN- } \\
10264\end{array}$ & FSR 400 & FSR 408 & $\begin{array}{c}\text { FLEXI- } \\
\text { FORCE }\end{array}$ & $\begin{array}{c}\text { FSG } \\
5 \mathrm{~N} 1 \mathrm{~A}\end{array}$ \\
\hline Size, mm & $57.3 \times 6.0$ & $5.08 \times 5.08$ & $609.2 \times 5.08$ & $9.53 \times 9.53$ & $5.0 \times 5.0$ \\
\hline $\begin{array}{l}\text { Max. Weight, } \\
\mathrm{N}\end{array}$ & 10 & 10 & 10 & 113.4 & 15 \\
\hline $\begin{array}{l}\text { Max. Output } \\
\text { value }\end{array}$ & $125 \mathrm{kOhm}$ & $100 \mathrm{kOhm}$ & $10 \mathrm{kOhm}$ & $40 \mathrm{MOhm}$ & $360 \mathrm{mV}$ \\
\hline
\end{tabular}

Sensors implemented using resistive technology have a number of limitations:

-Logarithmic dependence between the applied force and the change in resistance

-Possible effects of hysteresis

-Low reproducibility and stability of recorded signals

-Temperature dependence

Despite this, applied force sensors are useful in the TPROG electrode system, and the fact that their dimensions are small facilitates their management.

The sensor can be installed on any of the electrodes. It will allow controlling the pressing force of each electrode directly. The proposed method increases the reliability of the obtained values of the pressing force. It is possible to control the contact of each electrode.

As a rule, different versions of the bridge scheme are used in case of circuitry implementation of sensors based on elements with variable resistance (Fig.4). Based on the balance conditions in these circuits, resistors of the same or similar order as the upper limit of the sensing elements are used.

The use of bridge circuits powered by a DC voltage source is more common, but they introduce additional linearity errors. In addition, the remote location of the sensor results in a drop in the accuracy of the conversion. These errors can be reduced by applying the same circuitry to a DC source. In this case, two independent sources of current are required 
to register a signal from two sensors. This implementation assumes a low accuracy.

Most preferable is the use of a circuit that eliminates the nonlinearity of the increment in the output voltage from the increment of the resistive sensor. The circuit based on the operational amplifier is most suitable for solving this problem (Fig. 4c). Resistance of auxiliary resistors is selected equal to the upper limit of the resistance of the sensor. With a supply voltage of $5 \mathrm{~V}$, the dynamic range will be from 0 to $2.5 \mathrm{~V}$, which is convenient for subsequent signal transmission and its sampling.


Fig.4. Schemes of registration of applied force sensors signal.

In this work, we have used a registration scheme based on an amplifier. In the electrode system, a sensor was mounted on the measuring electrode.

\section{Results and Conclusion}

This study was performed in accordance with the Declaration of Helsinki and was approved by Local Committee of Biomedical Ethics of the Moscow Helmholtz Research Institute of Eye Diseases. Written informed consent was obtained from all participants.

The example of typical calibration characteristics is shown in Figure 5.

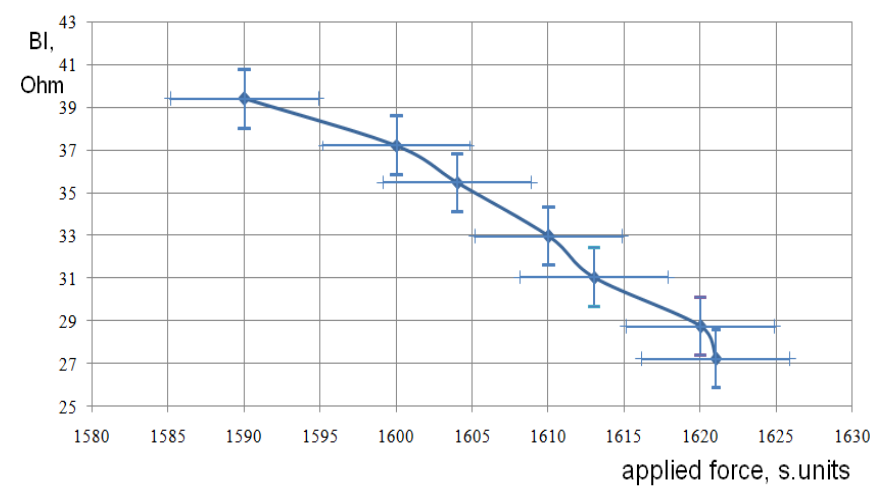

Fig. 5. Output data of the applied force sensor in TP-ROG.

The sensitivity and linearity of the resistive pressure force sensor was investigated by using the TP-ROG electrode system. Our research demonstrated that it is possible to register pressing forces from $55 \mathrm{~g}$ to $260 \mathrm{~g}$. The result will be used to correct the recorded values, taking into account the specific implementation of the force sensor.

When performing TP-ROG diagnostics, applied force control is necessary. Control is exercised by the applied force sensors, which are built in the electrode system of assignment. Before carrying out the tests, the system needs to be calibrated. In view of the irregular geometrical shape of an eye with the eyelid and because the sensor is mounted on a flexible surface and nestles in a soft substrate, calibration of only the applied force sensor is insufficient. For correct calibration, it is necessary to provide a possibility of direct control of the force applied to the eyelid. The system proposed in this work allows such control.

\section{Conflict of interest}

The authors declare that they have no conflicts of interest to disclose.

\section{Sources of Funding}

This study was supported by RFBR Grant (No. 18-08-01192).

\section{References}

1. Bettelheim H. [Oculorheography. A method for studies in intraocular circulation]. Albrecht Von Graefes Arch Klin Exp Ophthalmol. 1971;183(1):1-21. [Article in German].

2. Lazarenko VI. [Our method of functional rheography of eye]. Vestn Oftalmol. 1999;115(4):33-37. [Article in Russian]. 3. Avetisov ES, Katsnel'son LA, Savitskaia NF. [Rheocyclographic examinations in myopia]. Vestn Oftalmol. 1967;80(3):3-7. [Article in Russian].

4. Lazarenko VI, Komarovskikh EN. Results of the examination of hemodynamics of the eye and brain in patients with primary open-angle glaucoma. Vestn Oftalmol. 2004;120(1):32-36. [Article in Russian].

5. Luzhnov PV, Shamaev DM, Iomdina EN, Tarutta EP, Markosyan GA, Shamkina LA, et al. [Transpalpebral tetrapolar reoophtalmography in the assessment of parameters of the eye blood circulatory system. Vestn Ross Akad Med Nauk. 2015;70(3):372-7.

6. Shamaev DM, Luzhnov PV, Pika TO, Iomdina EN, Kleyman AP, Sianosyan AA. Applying Transpalpebral Rheoophthalmography to monitor effectiveness of the treatment of patients with glaucoma. International Journal of Biomedicine. 2016;6(4):287-289.

7. Shamaev DM, Luzhnov PV, Iomdina EN. (2018) Modeling of ocular and eyelid pulse blood filling in diagnosing using transpalpebral rheoophthalmography. In: Eskola H, Väisänen O, Viik J, Hyttinen J. (eds) EMBEC \& NBC 2017. EMBEC 2017, NBC 2017. IFMBE Proceedings, vol 65. Springer, Singapore.

8. Luzhnov PV, Shamaev DM, Iomdina EN, Markosyan GA, Tarutta EP, Sianosyan AA. (2018) Using quantitative parameters of ocular blood filling with transpalpebral rheoophthalmography. In: Eskola H, Väisänen O, Viik J, Hyttinen J. (eds) EMBEC \& NBC 2017. EMBEC 2017, NBC 2017. IFMBE Proceedings, vol 65. Springer, Singapore. 